\title{
PEMELIHARAAN CIRCULATING WATER PUMPS PADA PEMBANGKIT LISTRIK TENAGA GAS DAN UAP (PLTGU) BLOK 1 \\ PT. PEMBANGKIT JAWA BALI UNIT PEMBANGKIT MUARA KARANG
}

\author{
Popy Yuliarty dan Fachrurrozi \\ Program Studi Teknik Industri Universitas Mercu Buana \\ e-mail: popyyuliarty@yahoo.co.id
}

\begin{abstract}
ABSTRAK
Pada siklus tertutup PLTGU, air laut yang telah diolah dan dimurnikan, kemudian dilakukan pemanasan sehingga terbentuk uap yang pada dasarnya berfungsi sebagai penggerak turbin yang diteruskan ke generator sehingga menghasilkan arus listrik dan uap ini akan di kondensasikan kembali menjadi air yang lebih dikenal air kondensat. Pendinginan air kondesat terjadi pada kondensor, uap dari sistem gas turbin turun ke kondensor dan didinginkan dengan air laut yang dipompakan dengan Circulating water pumps. Adapun tujuan dari penelitian ini adalah mengetahui waktu perbaikan mesin Circulating Water Pumps dan mengetahui keandalan mesin Circulating Water Pumps pada PT. Pembangkit Jawa Bali (PJB) Unit Pembangkit Muara Karang agar dapat terjaga dengan baik untuk menghindari kerusakan. Metode yang digunakan dalam penelitian ini adalah metode mean time between failures (MTBF). Dari analisis diperoleh hasil bahwa perlu dilakukan service besar atau perawatan secara besar. Dan berdasarkan hasil analisis dengan nilai MTBF, Z dan standar deviasi waktu ovehaul mesin Circulating water pumps adalah 1058 jam atau 45 hari adalah waktu turun mesin yang andal yang harus dilakukan maintanance.
\end{abstract}

Kata Kunci: Pemurnian, Circulating Water Pumps, Metode Mean Time Between Failures

\begin{abstract}
In the closed-cycle PLTGU, sea water that has been processed and purified through a purification process, then performed the heating to form steam which basically serves as the driving force transmitted to the turbine generator to produce electricity and steam will be in condensation back into more familiar waters of water condensate. Cooling water condensate occurs in the condenser, where the steam from the gas turbine system down to a condenser and cooled with seawater that is pumped by circulating water pumps. The purpose of this study was to determine the engine repair time Circulating Water Pumps and determine the reliability of the machine Circulating Water Pumps in PT. Generating Java Bali (PJB) Muara Karang power plant unit to be maintained properly to avoid damage. The method used in this research is the mean time between failures (MTBF). From the analysis of the obtained results that need to be done a great service or major maintenance. And based on the analysis of the MTBF values, $Z$ and standard deviation Circulating water pumps machine overhaul time is 1058 hours or 45 days is a reliable machine down time to do maintenance.
\end{abstract}

Keywords: Purification, Circulating Water Pumps, Mean Time Between Failures Methods

\section{PENDAHULUAN}

Masalah utama dalam pembangkit tenaga listrik adalah pada sistem operasi yang disebabkan karena kerusakan pada sistem instalasi yang menyebabkan pemutusan tenaga sehingga pasokan listrik pun terputus. PLTGU (Pembangkit Listrik Tenaga Gas dan Uap) memerlukan pemeliharaan secara periodik, terutama pada bagian-bagian yang berhubungan dengan pipa-pipa air ketel uap (Evaporator) dan pipa-pipa air pendingin termasuk pipa-pipa kondensator. Pipa-pipa ini semua memerlukan pembersihan secara periodik.
Pada siklus tertutup PLTGU, air laut yang telah diolah dan dimurnikan melalui proses pemurnian, kemudian dilakukan pemanasan hingga terbentuk uap yang pada dasarnya berfungsi sebagai penggerak turbin yang diteruskan ke generator sehingga menghasilkan arus listrik dan uap ini akan di kondensasikan kembali menjadi air yang lebih dikenal air kondensat. Pendinginan air kondesat terjadi pada kondensor, dimana uap dari sistem gas turbin turun ke kondensor dan didinginkan dengan air laut yang dipompakan dengan Circulating water pumps. 
Melalui pelaksanaan pemeliharaan yang baik dan berkesinambungan maka peralatan perusahaan dapat dipergunakan sesuai dengan rencana, sehingga proses produksi dapat berjalan dengan lancar, dan kemungkinan kerusakan yang terjadi dapat dikurangi bahkan dihindari.

Adapun tujuan dari penelitian ini adalah mengetahui apakah perlu dilakukan perbaikan pada mesin Circulating Water Pumps dan berapa lama waktu yang dibutuhkan untuk melakukan kegiatan perbaikan tersebut.

\section{TINJAUAN PUSTAKA \\ Keandalan (Reliability)}

Keandalan adalah probabilitas suatu komponen atau sistem akan bekerja sesuai dengan fungsinya ketika dioperasikan selama periode waktu tertentu. Keandalan suatu komponen atau alat sebagai peluang bahwa komponen tersebut akan berfungsi sebagaimana mestinya selama paling sedikit sampai jangka waktu tertentu dalam keadaan percobaan tertentu [1].

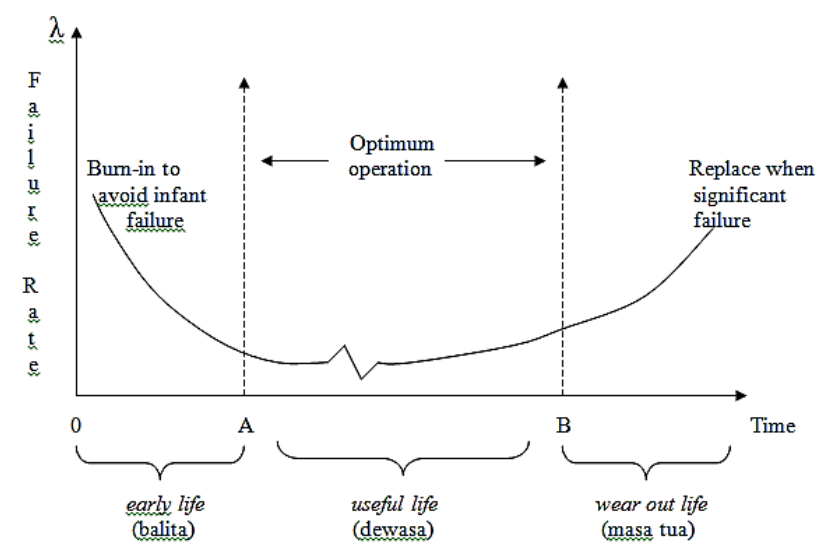

Gambar 1. Tipe kurva bak mandi [2]

Reliability sangat berkaitan dengan disain dari komponen mesin. Keandalan dari sebuah sistem tergantung dari keandalan komponen yang menyusun mesin tersebut [2]. Reliability ini tidak pernah mencapai $100 \%$. Tingkat kerusakan yang terjadi $(\lambda)$ akan berubah-ubah, seperti yang ditunjukkan dalam kurva bak mandi pada Gambar 1.

Pemeliharaan mesin bertujuan untuk menekan terjadinya kerusakan tidak terencana dengan total biaya perawatan dan perbaikan yang minimal [3]. Dalam analisis keandalan waktu kerusakan mesin ditentukan dengan konsep probabilitas yang menggunakan pendekatan beberapa bentuk distribusi statistik yang sesuai. Dengan diketahuinya parameterparameter distribusi waktu antara kerusakan seperti Mean Time Between Failure (MTBF) atau Mean Time To Failure (MTTF) maka diketahui rata-rata waktu operasi mesin keandalan dan laju kerusakan mesin, sedangkan waktu perbaikan digunakan untuk menghitung MTTR. Dari nilai MTBF/MTTF dan MTTR maka diketahui nilai availability mesin [4].

Selain itu, dalam pemeliharaan juga harus diperhitungkan aspek biayanya. Data biaya tenaga kerja, biaya penggantian komponen dan pelumasan mesin serta keuntungan yang hilang digunakan untuk menghitung biaya pemeliharaan ( $\mathrm{MC}=$ Maintenance Cost) dan biaya kerusakan (Failure Cost). Dari nilai keandalan mesin serta biaya pemeliharaan (MC) dan biaya kerusakan (FC) dapat dicari nilai optimalnya untuk menentukan interval perawatan mesin (S) yang meminimalkan total biaya (TMC) dengan nilai keandalan mesin yang maksimal [5].

\section{METODE PENELITIAN}

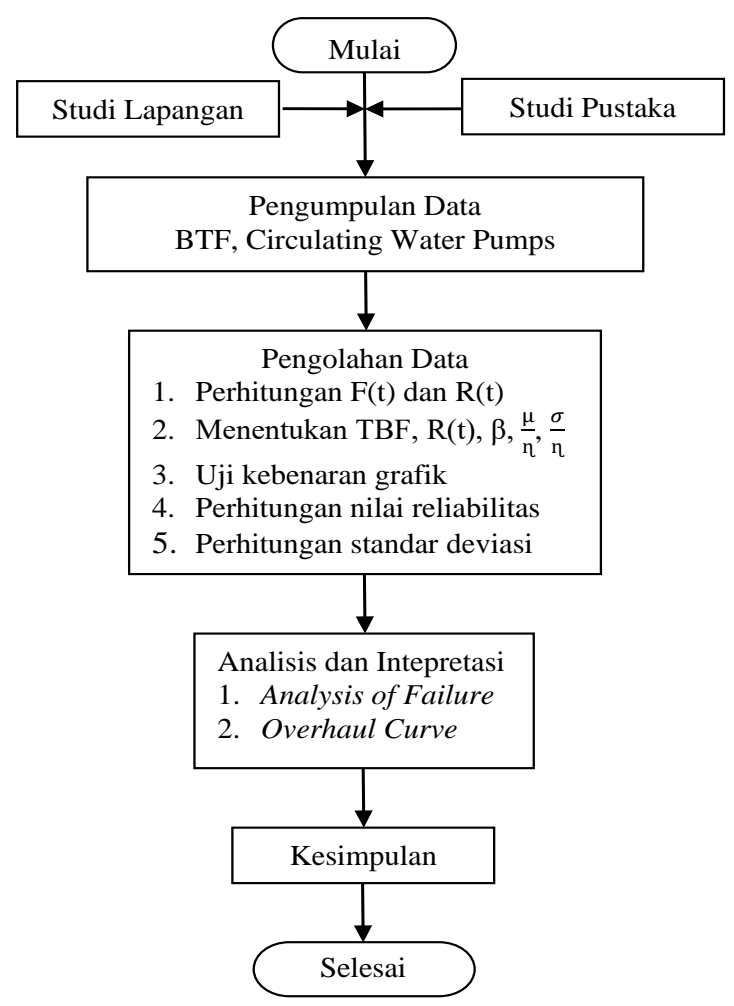

Gambar 2. Metodologi Penelitian 
Metode yang digunakan dalam penelitian ini adalah metode MBTF. Tahap selanjutnya adalah menganalisis hasil pengolahan data dan diakhiri dengan menyimpulkan hasil akhir penelitian serta merekomendasikan saran yang relevan dengan pembahasan sebelumnya.

\section{HASIL DAN PEMBAHASAN}

\section{Circulating water pumps (CWP)}

A. Fungsi Circulating Water Pumps

CWP merupakan pompa bertipe vertical centrifugal aliran axial mixed yang memiliki fungsi utama memompa air laut menuju tubetube condensor yang digunakan untuk mengkondensasikan uap keluaran Low Preasure (LP) turbin. Selain fungsi utama di atas CWP juga berfungsi untuk menyalurkan air laut ke suction pompa sea water booster pump (SWBP).

Spesifikasi mesin yang digunakan diperlihatkan dalam Tabel 1.

Tabel 1. Spesifikasi Mesin

\begin{tabular}{ll}
\hline \multicolumn{1}{c}{ Jenis Mesin } & \multicolumn{1}{c}{ Spesifikasi } \\
\hline Motor & YKKL1800-14/1730-1TH \\
Type & $1800 \mathrm{~kW}$ \\
Power & $425 \mathrm{r} / \mathrm{min}$ \\
Rated Speed & $6300 \mathrm{~V}$ \\
Voltage & $221.2 \mathrm{~A}$ \\
Current & $50 \mathrm{~Hz}$ \\
Frequency & $\mathrm{F}$ \\
Insulation Class & $24000 \mathrm{~kg}$ \\
Weight & IP 54 \\
Protection Class & \\
\hline Pompa & $1800 \mathrm{HLBK}-18$ \\
Type & $\mathrm{Q}=6,2-7,17-8,2 \mathrm{~m} 3 / \mathrm{s}$ \\
Capacity & $($ design point 7,17 m $/ \mathrm{s})$ \\
& $\mathrm{H}=19,8-18-15 \mathrm{~m}$ \\
Head & $($ design point $18 \mathrm{~m})$ \\
& $8,8-9,8-11,1 \mathrm{~m}$ \\
NPSH & $($ design point $9,8 \mathrm{~m})$ \\
& $425 \mathrm{r} / \mathrm{min}$ \\
Rated Speed & $1800 \mathrm{~kW}$ \\
Power &
\end{tabular}

Work Order (WO) Rutin Preventive PT. PJB UP Muara karang

Work Order rutin pada PT.PJB UP Muara Karang dilakukan atas dasar interval waktu (hari, minggu, bulan, jam operasi atau kali operasi) yang telah ditetapkan lebih dulu atau kriteria tertentu lainnya.
Bagian yang menjadi Routine Preventive Maintenance adalah:

a. Periksa Line Cooler, bila aliran kecil bersihkan Line.

b. Periksa Level Pelumas, tambah bila Level kurang.

c. Periksa Temperature Cooler.

Data Perhitungan $\mathrm{F}(t)$ dan $\mathrm{R}(\mathrm{t})$

Data TBF terdiri dari 20 data work order

$R(t)=\frac{[(N-n)+1]}{(N+1)}$

Dengan,

$\mathrm{R}(t)$ : Reliability

$\mathrm{N}$ : Jumlah data

n : urutan data (data yang ke...)

$R(t)=\frac{[(20-1)+1]}{(20+1)}$

$R(t)=\frac{19+1}{21}$

$R(t)=\frac{20}{21}=0,952$

Perhitungan Nilai $\mathrm{F}(\mathrm{t})$ menggunakan Persamaan 2 dan hasilnya terlihat pada Tabel 2.

Tabel 2. Data Perhitungan $\mathrm{F}(t)$ dan $\mathrm{R}(t)$

\begin{tabular}{cccc}
\hline TBF $($ Hour $)$ & $\mathrm{R}(\mathrm{t})$ & $\% \mathrm{R}(\mathrm{t})$ & $\mathrm{F}(\mathrm{t})$ \\
\hline 480 & 0,952 & 95,24 & 0,048 \\
552 & 0,905 & 90,48 & 0,095 \\
696 & 0,857 & 85,71 & 0,143 \\
720 & 0,810 & 80,95 & 0,190 \\
960 & 0,762 & 76,19 & 0,238 \\
1392 & 0,714 & 71,43 & 0,286 \\
1440 & 0,667 & 66,67 & 0,333 \\
1584 & 0,619 & 61,90 & 0,381 \\
1584 & 0,517 & 57,14 & 0,429 \\
1944 & 0,524 & 52,38 & 0,476 \\
2040 & 0,476 & 47,62 & 0,524 \\
2040 & 0,429 & 42,86 & 0,571 \\
2064 & 0,381 & 38,10 & 0,619 \\
2328 & 0,333 & 33,33 & 0,667 \\
2496 & 0,286 & 28,57 & 0,714 \\
2664 & 0,238 & 23,81 & 0,762 \\
3096 & 0,190 & 19,05 & 0,810 \\
3408 & 0,143 & 14,29 & 0,857 \\
3480 & 0,095 & 9,52 & 0,905 \\
3528 & 0,048 & 4,76 & 0,952 \\
\hline
\end{tabular}

$\mathrm{F}(t)=1-\mathrm{R}(t)$ 
$\mathrm{F}(t)=1-0,952$

$\mathrm{F}(t)=0,048$

$\mathrm{F}(t)=$ Failure rate

\section{Menentukan Nilai $\mu$}

Nilai $\mu$ didapat dari hasil perkalian antara nilai $\mu / \eta$ dengan nilai $\eta$, dengan hasil nilai $\mu$ adalah 1958 jam.

$\frac{\mu}{\eta} \times \eta=0,89 \times 2200=1958 \mathrm{jam}$

Jadi, $\mu=1958$ jam

\section{Perhitungan Nilai Uji Kebenaran Grafik}

Nilai Uji Kebenaran Grafik atau $\Delta$ didapat dari hasil bagi antara nilai $\mu-\bar{x}$ dibagi dengan nilai $\bar{x}$ yang hasilnya kemudian dikalikan dengan $100 \%$.

Hasil dari perhitungan $\Delta$ tersebut harus bernilai $\leq 20 \%$, maka hasil perhitungan akan dianggap valid dan data dapat diolah ke tahap berikutnya. Semakin kecil nilai $\Delta$ yang didapat dan paling mendekati $0 \%$ maka data grafik yang diperoleh semakin valid.

$$
\begin{aligned}
\Delta & =\left|\frac{\mu-\bar{X}}{\bar{X}}\right|=\left|\frac{1958-1924,8}{1924,8}\right|=0,0172=0,172 \\
\Delta & =1,72 \%
\end{aligned}
$$

Jadi, $\Delta=1,72 \%<20 \%$ berarti data itu benar dan boleh digunakan untuk melanjutkan ke proses selanjutnya.

\section{Perhitungan Nilai Reliability Function}

Nilai Reliability Function didapat dari nilai $\exp =2,7180$ dikalikan hasil bagi antara $-t$ dengan nilai $\eta$ yang kemudian dipangkatkan dengan nilai $\beta$.

$\mathrm{R}(\mathrm{t})=\exp \left(\frac{-t}{2200}\right)^{1,75}$

Apabila diketahui $t=2500$ maka untuk Reliability Function-nya adalah:

$$
\begin{aligned}
& \mathrm{R}(2500)=\exp \left(\frac{-2500}{2200}\right)^{1,75} \\
& \mathrm{R}(2500)=2,7183^{(-1,14)^{1,75}} \\
& \mathrm{R}(2500)=2,7183^{(-1,26)} \\
& \mathrm{R}(2500)=\frac{1}{2,7183^{(1,26)}} \\
& \mathrm{R}(2500)=\frac{1}{3,52} \\
& \mathrm{R}(2500)=0,308
\end{aligned}
$$

$$
\mathrm{R}(2500)=30,8 \%
$$

Perhitungan Standar Deviasi

$\sigma(s)=\sqrt{\frac{\sum(\bar{X}-X i)^{2}}{n-1}}$

$\sigma(s)=\sqrt{\frac{(1924-480)^{2}+\cdots+(1924-3528)^{2}}{20-1}}$
$\sigma(s)=980,27$

\section{Overhaul Curve}

Menentukan MDT 1 dan MDT 2 dari data yang telah dikumpulkan.

$$
\text { MDT } 1=16 \text { dan MDT } 2=5
$$

Maka, $\frac{M D T 2}{M D T 1}=\frac{5}{16}=0,3125$

Untuk menentukan apakah terdapat selang perbaikan optimal pada circulating water pumps dimasukan ke grafik pemeriksaan yang masih kosong. Asal Nilai $\beta$ didapatkan dari hasil penentuan Nilai $\beta$ dengan nomograf yang telah ditentukan sebelumnya di atas dan Nilai MDT didapat dari jenis kerusakan pada circulating water pumps, MDT1 adalah jenis kerusakan yang tidak direncanakan sedangkan MDT 2 adalah kerusakan yang direncanakan. Maka nilai MDT(1) maupun MDT(2) telah diberikan sebesar $\mathrm{MDT}(1)=16$ dan $\mathrm{MDT}(2)=5$.

Dikarenakan circulating water pumps ini harus dilakukan service besar maka harus diketahui lamanya waktu operasi sebelum dilakukan perbaikan dengan memasukan ke grafik (Z, MDT 2/MDT 1).

Menentukan waktu overhaul atau To dengan cara:

Diketahui:

$$
\begin{aligned}
& \eta=2200, \\
& \mu(\mathrm{MTBF})=1958 \text { jam, } \\
& \sigma=1056 \text { jam, } \frac{M D T 2}{M D T 1}=0,3125 \\
& \mathrm{Z}_{(\text {MDT 2/MDT 1) }}=\mathrm{Z}_{(0,31)}=-0,89 \\
& =\frac{T o-M T B F}{\sigma} \\
& Z \sigma=\text { To }- \text { MTBF }
\end{aligned}
$$$$
Z=\frac{T o-M T B F}{\sigma}
$$ 


$$
\begin{aligned}
& \text { To }=Z \sigma+\mathrm{MTBF} \\
& \text { To }=\mathrm{MTBF}+Z \sigma \\
& \text { To }=1958+(-0,89) \times 980 \\
& \text { To }=1958-872,2=1085 \text { hours }
\end{aligned}
$$

\section{Data Time Between Failure (TBF)}

Dari hasil pengumpulan data yang telah dilakukan terdapat 20 data TBF yang siap diolah, untuk mengetahui waktu mesin beroperasi setelah diperbaiki hingga mengalami kerusakan kembali itulah yang disebut dengan TBF. Dimana terdapat waktu mesin operasi yang cukup bervariasi dan waktu tersebut kami dapat berdasarkan perhitungan tanggal dimulainya mesin bekerja setelah diperbaiki hingga mesin tersebut mengalami kerusakan kembali.

Pada waktu mesin beroperasi yang pertama kami mendapatkan waktu 1584 jam atau selama 66 hari, 10 minggu dan 2 bulan yang dimulai pada tanggal 24 November 2008 (mesin setelah diperbaiki dan mulai beroperasi kembali) hingga tanggal 14 Februari 2009 (mesin mengalami kerusakan kembali dan mulai diperbaiki). Mesin diperbaiki dan breakdown selama 14 hari, sehingga pada tanggal 08 Desember 2008 mesin dapat beroperasi kembali seperti sebelumnya. Hal ini berlangsung terus-menerus selama 20 kali waktu mesin beroperasi dari mesin setelah diperbaiki dan dapat beroperasi hingga mesin tersebut mengalami kerusakan kembali dan waktu yang keseluruhan untuk 20 data yang didapat adalah selama 5 tahun yaitu dimulai pada akhir tahun 2008 (08 Desember 2008) hingga akhir 2014 (24 September 2012).

\section{Perhitungan $\mathbf{F}(\mathrm{t})$ dan $\mathbf{R}(\mathrm{t})$}

Berdasarkan waktu mesin beroperasi (TBF) yang didapat sebanyak 20 data, dimana ke-20 data tersebut masih acak dan diurutkan berdasarkan tanggal kejadian. Untuk melakukan perhitungan $\mathrm{F}(t)$ dan $\mathrm{R}(t)$ data harus diurutkan mulai dari data yang terkecil (480 jam) hingga data yang terbesar (3528 jam), kemudian data tersebut barulah dapat diolah dan perhitungan pertama yang dilakukan adalah perhitungan $\mathrm{R}(\mathrm{t})$ dengan pembagian hasil pengurangan jumlah data (20 data) dengan data ke-n $(n=1,2,3, \ldots, 20)$ dan ditambah dengan satu lalu barulah dibagi dengan hasil penjumlahan jumlah data (20 data) ditambah dengan 1 . Pada data ke-n $(\mathrm{n}=1)$ didapatkan hasil 0,952 data tengah $(\mathrm{n}=10)=$ 0,524 dan data akhir $(\mathrm{n}=20)=0,048$.

Setelah ke-20 data tersebut dihitung nilai $\mathrm{R}(t)$-nya maka tahap berikutnya adalah perhitungan nilai $\mathrm{F}(t)$ dengan hasil pengurangan antara 1 dengan nilai $\mathrm{R}(t)$ dan pengurangan nilai $\mathrm{R}(t)$ tersebut disesuaikan dengan masingmasing subgrup data. Hasil perhitungan $F(t)$ $\mathrm{n}=1$ adalah $0,048, \mathrm{n}=8$ adalah 0,476 dan $\mathrm{n}=20$ adalah 0,952, dimana untuk hasil perhitungan $\mathrm{F}(t)$ selalu hasil nilai kebalikan pada perhitungan $\mathrm{R}(t)$, data awal $\mathrm{n}=1$ untuk $\mathrm{R}(t)$ dan $\mathrm{F}(t)$ adalah 0,952 dan 0,048, data akhir $\mathrm{n}=20$ untuk R(t) dan F(t) adalah 0,048 dan 0,952.

\section{Menentukan Nilai $\beta$}

Dalam menentukan nilai $\beta$ titik perpotongan garis berada di antara nilai $\beta=2,0$ dan $\beta=1,5$ dimana nilai terbawah $\beta=0,5$. Titik perpotongan garis tepat berada di atas nilai $\beta=$ 1,7 dan di bawah nilai $\beta=1,8$ dan setelah dirinci kembali titik perpotongan garis tersebut berada pada nilai $\beta=1,75$.

\section{Perhitungan Nilai $\frac{\mu}{\eta}$}

Nilai $\frac{\mu}{\eta}$ yang didapat adalah 0,89 , dimana nilai tersebut didapat dari titik perpotongan garis yang berada diantara nilai $\frac{\mu}{\eta}$ atas titik perpotongan garis $=0,8855$ dan nilai $\frac{\mu}{\eta}$ bawah titik perpotongan garis $=0,90$. Hasil pengurangan nilai $\frac{\mu}{\eta}$ bawah dengan atas titik perpotongan garis $=0,89$ dengan jumlah garis antara nilai $\frac{\mu}{\eta}$ bawah dengan atas titik perpotongan garis $=6$, setelah kedua nilai tersebut didapat maka hasil pengurangan sebelumnya dibagi dengan jumlah garis yang hasilnya 0,00075 . Untuk mencari nilai $\frac{\mu}{\eta}$ maka, nilai $\frac{\mu}{\eta}$ atas titik perpotongan garis $=0,8855$ ditambah dengan hasil perkalian nilai $=0,00075$ dengan hasil nilai $\frac{\mu}{\eta}$ adalah 0,89 .

\section{Perhitungan Nilai $\mu$}


Nilai $\mu$ didapatkan dari hasil perkalian antara nilai $\frac{\mu}{\eta}=0,89$ dengan nilai $\eta=2200$ dan hasil nilai $\mu=1958$ jam.

\section{Perhitungan Nilai Uji Kebenaran Grafik}

Nilai uji kebenaran grafik atau $\Delta$ dicari dengan hasil pengurangan anatara nilai $\mu=$ 1958 dengan nilai $\bar{x}=1924$ yang hasilnya adalah 1, kemudian dibagi dengan nilai $\bar{x}=$ 1924 dengan hasil 0,0172 dan dikalikan dengan 100\% maka hasil nilai uji kebenaran grafik adalah 0,07391 1,72\%. Pada hasil perhitungan nilai uji kebenaran grafik harus berada pada rentang nilai $0 \%<x<20 \%$ dan pada saat ini nilai uji kebenaran grafik yang ada beda pada $(0 \%<1,72 \%<20 \%)$ nilai yang didapat terbilang sangat kecil yang mengindikasikan bahwa semakin kecil nilai uji kebenaran grafik dan mendekati nilai $0 \%$ maka nilai yang dihasilkan pada pengolahan data akan semakin lebih valid. Apabila nilai uji kebenaran grafik berada dibawah $0 \%$ atau lebih besar dari 20\% maka data yang didapat terbilang tidak valid dan perlu dilakukan penambahan atau pengambilan data kembali.

\section{Perhitungan Nilai Reliability Function}

Nilai Reliability Function atau $\mathrm{R}(\mathrm{t}) \Delta$ yang ada sebelumnya apabila nilai $-t$ belum diketahui maka nilai akhir untuk Reliability Function masih dalam bentuk rumus yang didapat dari hasil perkalian nilai $\exp =2,7180$ dengan hasil bagi antara nilai $-t$ dengan nilai $\eta$ $=2200$ yang sudah dipangkatkan sebelumnya dengan nilai $\beta=1,75$. Nilai $-t$ diketahui adalah 2500 maka hasil bagi nilai $-t$ dengan nilai $\eta$ adalah 0,984 yang kemudian dipangkatkan dengan nilai $\beta$ yang hasilnya menjadi 1,14 dan pada tahap akhir barulah dikalikan dengan nilai exp, maka nilai Reliability Function adalah 3,09825.

\section{Analysis of Failures}

Pada tahap analysis of failures ini dilakukan setelah data TBF diurutkan, perhitungan baik perhitungan $\mathrm{F}(t)$ dan $\mathrm{R}(t)$ serta standar deviasi telah dihitung sebelumnya, maka diketahuilah hasil observations data, dimana pada sampel statistik terdapat nilai $\bar{X}=$
1924 hrs dan untuk nilai $s$ adalah $s=980$ hrs. Pada nilai theoretical distribution parameters terdapat nilai $\eta=2200, \beta=1,75, \frac{\mu}{\eta}=0,89, \frac{\sigma}{\eta}=$ 0,48 (hasil bagi dari nilai $\sigma=1056$ dibagi dengan nilai $\eta=2200$ ), nilai $\mu$ sama dengan nilai MTBF dimana nilai $\frac{\mu}{\eta}=0,89$ dikalikan dengan nilai $\eta=2200$, maka hasilnya adalah 1958 hrs, dan yang terakhir adalah Reliability Function $R(t)=\exp \left(\frac{-t}{2200}\right)^{1,75}$.

\section{Grafik Hubungan $\boldsymbol{\beta}$ dengan MDT}

Pada grafik ini terdapat garis diagonal dimulai dari titik ( $x ; y)$ yaitu (MDT(2)/MDT(1)); $\beta)$ terbawah hingga garis diagonal tersebut melintang ke atas ke arah kanan, dari garis diagonal tersebut terdapat dua daerah yang terbentuk dimana pada daerah di atas garis diagonal merupakan daerah schedule overhauls dan pada daerah kedua yang berada di bawah garis diagonal merupakan daerah repair or replace only at failure (perbaikan atau ganti hanya pada kegagalan). Kedua daerah ini memiliki sifat yang berbeda satu sama lain, pada daerah pertama yaitu schedule overhauls mengindikasikan bahwa titik plot yang dihasilkan berdasarkan perhitungan berada di daerah ini, maka perlu dilakukan service besar atau perawatan secara besar (penggantian mesin lama ke mesin baru apabila diperlukan), berbeda dengan daerah kedua yaitu daerah repair or replace only at failure berada di bawah garis kurva yang mengindikasikan bahwa titik plot yang dihasilkan berdasarkan perhitungan berada di daerah ini, maka hanya perlu dilakukan perbaikan skala kecil saja atau penggantian part kecil yang mengalami kerusakan.

Pada data yang didapat letak plot berada pada daerah pertama dengan nilai $\frac{M D T(2)}{M D T(1)}=\frac{5}{16}=$ 0,3125 sebagai sumbu $x$ dan nilai $\beta=1,75$ sebagai sumbu $y$, maka berdasarkan data yang didapat pada daerah pertama yaitu schedule overhauls mengindikasikan bahwa titik plot yang dihasilkan berdasarkan perhitungan berada di daerah ini, maka perlu dilakukan service besar atau perawatan secara besar (penggantian mesin lama ke mesin baru apabila diperlukan). 


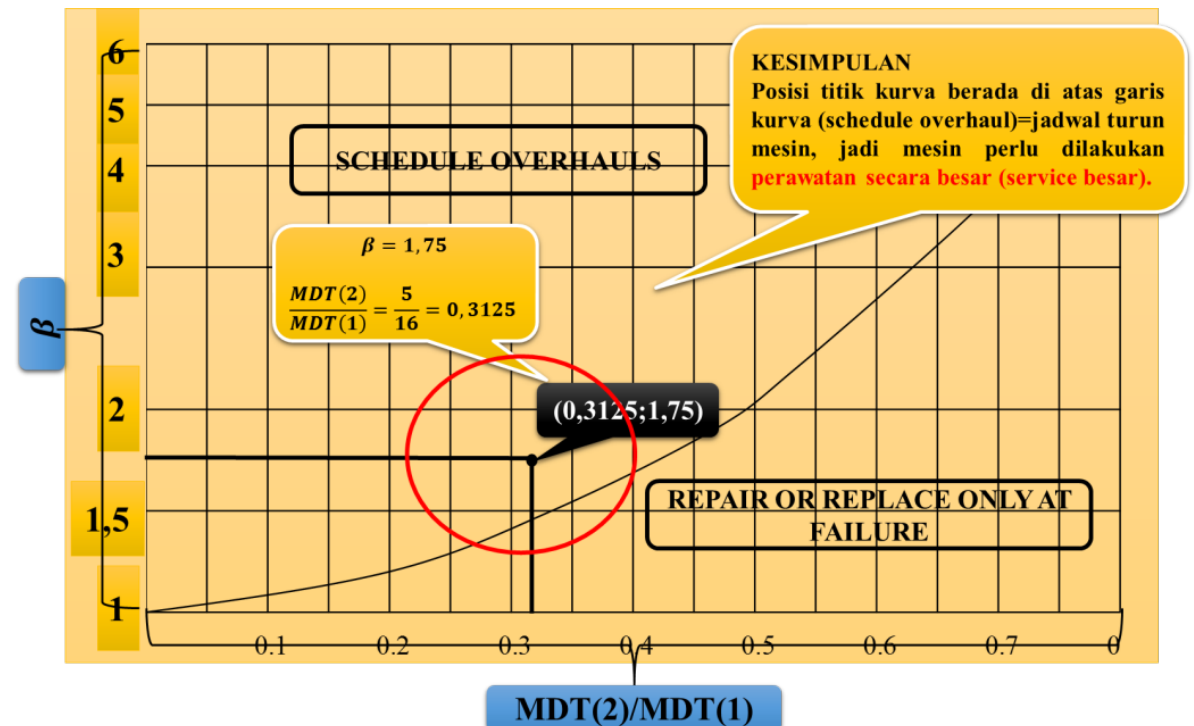

Gambar 3. Curve to Determine If an Optimal Overhaul Interval Exist

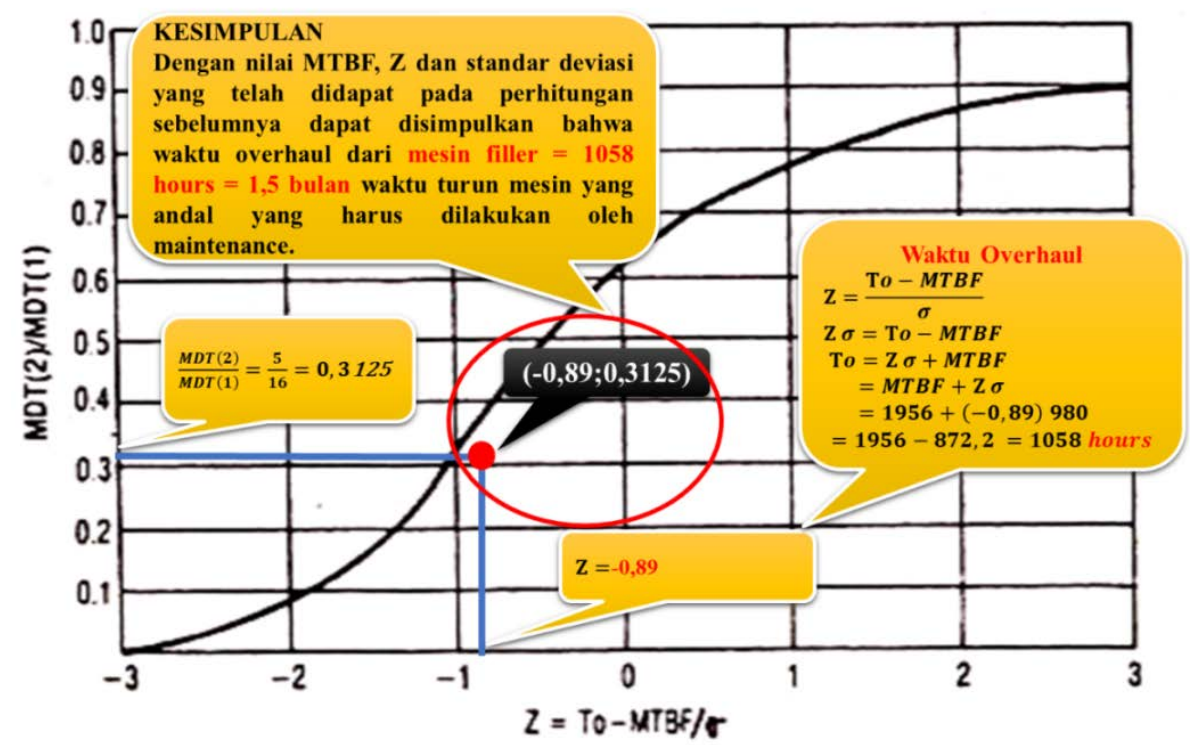

Gambar 4. Curve to Find Optimum Overhaul Interval

\section{Grafik untuk Menemukan Selang Perbaikan Optimal}

Pada grafik ini terdapat garis diagonal dimulai dari titik $(x ; y)$ yaitu $(Z=$ $\left.\frac{T o-M T B F}{\sigma} ; \operatorname{MDT}(2) / M D T(1)\right)$ terbawah hingga garis diagonal tersebut melintang ke atas ke arah kanan, namun berbeda pada grafik sebelumnya selain tidak membentuk dua daerah yang berbeda garis diagonal melintang yang ada juga cenderung melambung ke atas dan plot yang dibuat akan selalu berada pada garis yang ada. Berdasarkan data yang ada plot yang terbentuk berada di nilai $\mathrm{Z}=-0,89$ (yang didapat dari tabel Distribusi Frekuensi) sebagai sumbu $x$ nya dan nilai $\frac{M D T(2)}{M D T(1)}=\frac{5}{16}=0,3125$ sebagai sumbu $y$ nya. Untuk mengetahui waktu overhaul dari mesin filler maka perlu dilakukan perhitungan waktu overhaul itu sendiri dengan menggunakan rumus $Z=\frac{T o-M T B F}{\sigma}$ yang berubah menjadi $Z \sigma=$ To - MTBF dan pada tahap akhir adalah mencari nilai To nya maka rumusnya menjadi $T o=M T B F+Z \sigma$, dimana nilai $\mathrm{MTBF}=1958 Z=0,89$, dan nilai $\sigma=980$. Hasil perhitungan nilai To adalah 1085 jam (45 hari) waktu turun mesin yang andal yang harus dilakukan oleh seorang maintenance. 


\section{KESIMPULAN}

Dari hasil analisis diperoleh hasil bahwa perlu dilakukan service besar atau perawatan secara besar. Dan berdasarkan hasil analisis dengan nilai MTBF, Z dan standar deviasi waktu perbaikan atau overhaul mesin Circulating water pumps adalah 1058 jam atau 45 hari.

\section{DAFTAR PUSTAKA}

[1]. Nakajima, Seiichi, 1988, Introduction to Total Productive Maintenance, Productivity Press, Inc., Cambridge, Massachusetts.

[2]. Moubray, John, 1997, Reliability Centered Maintenance, Second Edition, Penerbit Industrial Press Inc, New York.

[3]. Kathleen, E.M, 1999, TPM : A Contextual View, Journal of Operation Management 17, Minneapolis, USA.
[4]. Maggard, Bil.N.P.E, 1992, TPM Maintenance Operations That Works, The Theory and Design of TPM, A Guide For Implementing TPM, TPM Press, Inc., USA.

[5]. Nakajima, Seiichi, 1994, Maintenance Management, Productivity Press, Inc., Cambridge, Massachusetts.

[6]. Nakajima, Seiichi dan Benjamin, S.B, 1989, TPM Development Program Implementing Total Productive Maintenance, Productivity Press, Inc., Cambridge, Massachusetts. 